\title{
Using Improved Entropy-Cloud Model to Select High-Speed Railway Express Freight Train Service Sites
}

\author{
Wencheng Huang ${ }^{1,2,3}$ and Bin Shuai ${ }^{1,2}$ \\ ${ }^{1}$ School of Transportation and Logistics, Southwest Jiaotong University, Chengdu, Sichuan 610031, China \\ ${ }^{2}$ National United Engineering Laboratory of Integrated and Intelligent Transportation, Southwest Jiaotong University, Chengdu, \\ Sichuan 610031, China \\ ${ }^{3}$ Traffic and Transportation Engineering Experiment and Comprehensive Innovation Center, Southwest Jiaotong University, Chengdu, \\ Sichuan 610031, China \\ Correspondence should be addressed to Wencheng Huang; hwc2014200864@my.swjtu.edu.cn
}

Received 2 August 2017; Accepted 17 October 2017; Published 9 November 2017

Academic Editor: Konstantinos Karamanos

Copyright (C) 2017 Wencheng Huang and Bin Shuai. This is an open access article distributed under the Creative Commons Attribution License, which permits unrestricted use, distribution, and reproduction in any medium, provided the original work is properly cited.

\begin{abstract}
High-speed railway (HSR) express freight train service sites selection is critical to the development of China's Third Party Logistics market. In this paper, we formulate an improved entropy-cloud model based approach to solve the HSR express sites selection problem for the first time. The basic data of the indicators, for example, existing railway network conditions, traffic environment, express freight market demand, and policy, will be used as the inputs. We apply improved entropy method to obtain each subindicator's weight. The cloud model will be used to select and classify each station under evaluation.
\end{abstract}

\section{Introduction}

With the rapid development of China's economy, the demand for Third Party Logistics (TPL) among regional centers keeps increasing, especially for high value-added goods, for example, foods and drinks, electronics, medical supplies, and textile. The goods owners would rather afford to pay higher transport costs for transport service that is convenient, time-saving, and reliable than vice versa. The high-speed railway (HSR) has a lot of advantages such as large transport capacity, low energy consumption, punctual operation, safety, and reliability, which satisfies the requirements of the TPL transportation. There is a huge potential to develop the HSR express serving for the TPL. Also, it is one of the most important strategic planning for China railway to obtain more shares in high value-added goods transportation market.

The high-speed trains provide TPL service based on the HSR express network; the network is formed with sites and edges. In this paper we focus on selecting and classifying the possible HSR stations existing in China. For each HSR station, there are three choices considered: selecting and developing as a high-speed railway express logistics center
(LC), selecting and developing as a high-speed railway express logistics base (LB), or no TPL service. The cargos are gathered to the LC and LB by roadway or railway. Each selected site will serve one area so the sites must be located in central cities of each logistics area.

In this paper we formulate a new approach based on improved entropy-cloud model (IECM) to solve the HSR express sites selection problem (SSP). After analyzing the factors related to the high-speed railway express SSP, for example, the existing railway network conditions, traffic environment, express freight market demand, and policy, we try to explain the internal development law of the sites, plan the layout and location of the sites, and divide the level of the sites according to the actual TPL demand. The remainder of this paper is organized as follows. In Section 2, we give a detailed literature review on railway express SSP. Section 3 is devoted to the description of the railway express freight train SSP evaluation indicators; the data of the indicators will be applied as the inputs of the proposed approach. Section 4 is devoted to introducing the translation-corrected improved entropy-cloud model, including formulation, proof, and the SSP outputs of the approach. In Section 5 we give the 
comparison analysis and results discussions of the case study. Section 6 presents the major conclusions and gives an outline of future research tasks.

\section{Literature Review}

This section presents a review of the railway sites selection problem literature that provides the background and establishes a framework for this research. This section also identifies the contributions of the research presented in this paper. First, we will introduce the related literatures about the railway and intermodal hub-and-spoke network design problem. Then, we will introduce other approaches which are used to solve the railway sites selection problem. After that, we will give a conclusion about the existing literatures, as well as the contributions and objectives about the approach used in this paper.

Most of the researches formulate the railway express SSP as a hub-and-spoke network [1] or intermodal hub-andspoke network design problem [2-6]. The hub-and-spoke network problem was originally formulated to be a quadratic integer programming model by O'Kelly [7] and then later is referred to as a $p$-hub median problem by Campbell [8]. The $p$-hub median problem aims to select $p$ hub facilities from a set of available candidates, to allocate spoke nodes to hubs and to simultaneously route freight flows. There are two kinds of mathematical models to formulate the hub-and-spoke network problem, including path-based mixed integer linear programming models with four-dimensional variables (e.g., [9-12]) and origin-based mixed integer linear programming models with three-dimensional variables (e.g., [13-15]). Meng and Wang [3], both, apply a mathematical program with equilibrium constraints model for the intermodal hub-and-spoke network design problem with multiple stakeholders and multitype containers. There are two main contributions about the model: formulating the user equilibrium (UE) behavior of intermodal operators in route choice for any given network design decision of the network planner and using a cost function that is capable of reflecting the transition from scale economies to scale diseconomies in distinct flow regimes for carriers or hub operators. A hybrid genetic algorithm (HGA) was proposed to solve the model. From a network design perspective, Alumur et al. [4] proposed a linear mixed integer programming model which considered transportation costs and travel time to solve the multimodal hub location and hub network design problem. Considering the same mixed uncertainties in both transportation cost and travel time, Yang et al. [5] developed a novel modeling framework for the intermodal hub-and-spoke network design problem to jointly minimize the expected value of total transportation costs and the maximum travel time requirement in term of critical value. A new hybrid methodology by combining fuzzy random simulation (FRS) technique and multistart simulated annealing (MSA) algorithm was designed to solve the proposed model. Serper and Alumur [6] applied a mixed integer programming model and a variable neighborhood search algorithm to determine the locations and capacities of hubs, which are transportation modes to serve at hubs, allocation of nonhub nodes to hubs, and the number of vehicles of each type to operate on the hub network to route the demand between origin-destination pairs with minimum total cost. There are four kinds of costs in the objective function including fixed costs of establishing hubs with different capacities, purchasing and operational costs of vehicles, transportation costs, and material handling costs. Jeong et al. [1] applied the hub-and-spoke network in railways for the first time, where a central planner is to find transport routes, frequency of service, length of trains to be used, and transportation volume. A linear integer programming model whose objective function includes not only the typical operational cost, but also cost due to the transit time spent by freight in the network is established to formulate the problem, and heuristic algorithms were used to solve large-scale instances occurring in European rail freight systems. In order to solve the hub-and-spoke service network design problem for express freight train running between railway logistic terminals, Hai et al. [16] applied the Principal Component Analysis (PCA) to determine the node's level of the regional logistics hub-and-spoke network. They considered influence factors including GDP, population, number of industrial enterprises, industrial added value, total retail sales of social consumer goods, highway mileage, inland navigation mileage, railway operation mileage, and so on. Sun and Li [17] used Fuzzy Cluster Analysis (FCA) to classify the railway express stations' level. FCA involves four steps: establishing evaluation indicators system, dimensionless processing, and establishing fuzzy relation and fuzzy cluster. Huang et al. [18] established a mixed integer linear programming model to minimize the total operation costs, including fixed costs, variable costs, and penalty cost, and designed a genetic algorithm to solve the model and the scale of the problem.

Moreover, some other approaches have also been applied to solve the railway SSP. Yin et al. [19-21] established three different mixed integer programming models to solve railway baggage and parcel logistics base and distribution sites problem. Three different algorithms were designed to solve the problems, including a heuristic algorithm combined scan and local search [19], a two-stage method combined improved scan method and iterative method [20], and a two-stage method combined scan search and tabu search algorithm [21]. AHP transforms a flexible multicriteria decision-making problem into a hierarchy with respect to one or more criteria. It has been widely used for a variety of sites selection problem; for example, Mohajeri and Amin [22] applied the methods of AHP and data envelopment analysis (DEA) to find the optimum site for a railway station. There are four main criteria in that paper, including rail-related, passenger services, architecture and urbanism, and economics. There are also 26 subcriteria as well as five alternatives. The comparison matrices of AHP were used to obtain the weights and priorities of the railway station candidates and a DEA model was proposed to determine the optimum site for a railway station. Bersani et al. [23] proposed an AHP based methodological approach to evaluate the optimal locations to install a Train Conformity Check System (TCCS) on a railway section. Ballis [24] used AHP to select the airport-site location on the Island of Samothraki, Greece. The AHP method has also been used for transshipment site selection [25] and transit site selection 
[26]. Since a few years ago, artificial intelligence and expert systems have been used in the SSP for searching the appropriate solutions, such as Geographic Information System (GIS); see Padmaja et al. [27]. There are three steps for a SSP. (i) Create vulnerability map with various factors. (ii) Create P map and I map to apply the equation of Pts map. (iii) GIS software locates the best sites. Yu et al. [28] proposed an approach to deal with the hub location problem in urban public transit network design. Firstly, they introduced an indicator defined as passenger attraction to describe the attraction level of a transit node to passenger. Secondly, a mathematical model aimed at maximizing served populations per construction cost was proposed to optimize multihub location based on the selected candidate nodes. Dimitriou [29] applied hierarchical variational inequalities programming to optimal competitive freight network design problem. The key points are the particularities emerging in this case of transportation facilities strategic, operational planning, multiple game-theoretic, and equilibrium problems that are structured in cascade and in hierarchies. In order to study the integrated tactical planning of hub locations and the design of a frequency service network, Rothenbacher et al. [30] presented a pathbased model and solved it with a branch-and-price-and-cut algorithm. The constraints in the model included multiple transshipments of requests at hubs, transport time limits for requests, request splitting, and outsourcing possibilities.

From the above literatures, we can find the following. (i) Most of the researchers try to select the sites by using a transportation costs based optimization model, or travel time based optimization model, or both. They did not consider the service market demand, railway development level, integrated transportation convergence development level, and so on. (ii) Some researchers determine the node's level by considering the GDP, population, number of industrial enterprises, industrial added value, total retail sales of social consumer goods, highway mileage, inland navigation mileage, railway operation mileage, and so on, but they did not consider their influence on the related policies. (iii) Some approaches, methods, and techniques (e.g., AHP) require experience and knowledge from the evaluators and experts; sometimes the calculation results are subjective and inaccurate. In this paper we will formulate an IECM to solve the HSR express SSP. First, we will introduce the study areas and minimum research unit in China. Then we formulate the SSP evaluation indicators, including HSR express freight train service market demand, HSR development level, integrated transportation convergence development level, and the related policies. The collected data about the indicators will be used as the inputs for the evaluation. The improved entropy method will be applied to obtain the weight for each indicator. Compared with AHP, the improved entropy method is more objective and accurate. Then the cloud model will be applied to select and classify the HSR express freight service sites.

\section{HSR Express Freight Train SSP Evaluation Indicators: The Inputs}

China has 34 provinces, with different economic development and HSR operated lines length. In order to establish the HSR express freight train SSP evaluation indicators system, we divide the whole China into 8 first-class logistics areas, including Pearl River Delta (Guangxi, Guangdong and Hainan Province), Yangtze River Delta (Anhui, Jiangsu, Shanghai and Zhejiang Province), North China (Inner Mongolia and Shanxi Province), Northeast China (Heilongjiang and Jilin Province), Bohai logistics area (Beijing, Tianjin, Hebei, Liaoning, and Shandong Province), Central China (Henan, Hubei, Hunan, Jiangxi, and Fujian Province), Southwest China (Xizang, Sichuan, Yunan, Chongqing, and Guizhou Province), and Northwest China (Xinjiang, Qinghai, Gansu, Ningxia, and Shanxi Province). We then divide each first-class logistics area into several second-class logistics areas; see Figure 1. In this paper we focus on how to select and classify the HSR express freight train service station in the second-class logistics areas scale. For each second-class logistics area $i$, we establish the HSR express freight train SSP evaluation indicators system, which includes 4 first-class indicators and 15 second-class indicators as described below.

(i) HSR Express Freight Train Service Market Demand. There are 6 subindicators of the HSR express freight train service market demand: gross domestic product (GDP), regional industrial added value, number of large enterprises, total import and export trade value in the region, total retail sales of social consumer goods, and regional trade volume. GDP reflects the result of all local resident units in a certain period of time. Different levels of areas with different GDP are suitable for the construction of different levels of logistics center, because of the close relationship between logistics demand and GDP. We use the regional industrial added value to formulate the huge role for industry and related businesses on the logistics needs and apply the number of large enterprises to measure the important impact on the operation of the logistics centers by the potential large number of customers. Because the size of customers is the main service object of the railway logistics centers, the larger customers scale is conducive for the construction of highlevel logistics centers. We use the total import and export trade value in the region to formulate the development of international trade, which is one of the most important evaluation indicators. We also use total retail sales of social consumer goods to formulate the national economy of the relevant industries to the social groups and residents supply sales of consumer goods, which reflects the final decision. Also, we apply the regional trade volume to reflect the demands of the transportation and logistics; the high-level logistics centers are suitable to establish in the regions with large-scale transport demands.

(ii) HSR Development Level. There are 3 subindicators of the HSR development level: HSR station's integrated operational assessment index, HSR operational line length, and HSR total investment in fixed assets. The first subindicator reflects the integrated operational conditions of the HSR stations. The second subindicator shows different HSR logistics scale has different logistics operation level. The third subindicator shows the HSR development potential, which influences the development of the HSR logistics. 


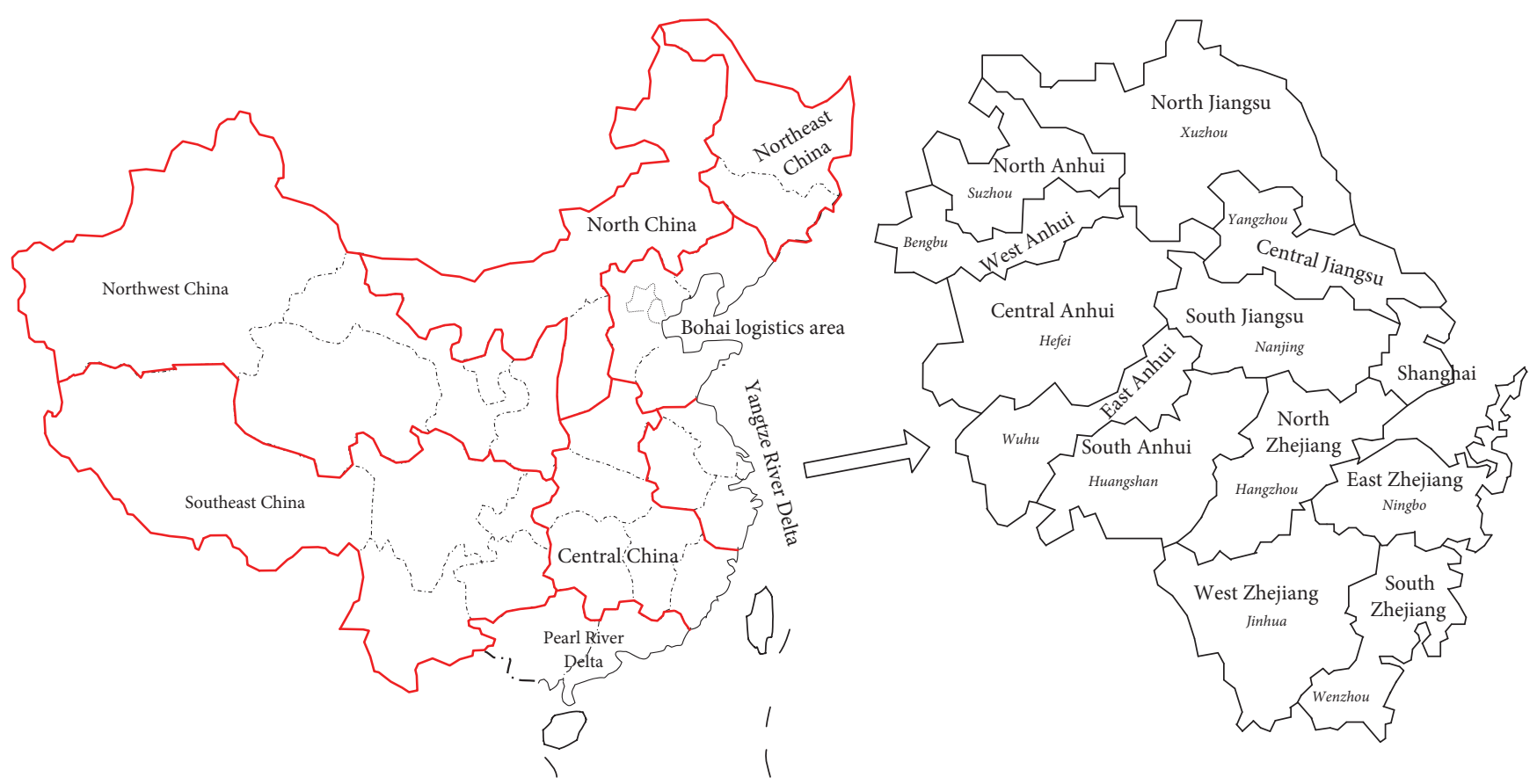

FIgURE 1: Layout of 8 first-class logistics areas and second-class logistics areas (using Yangtze River Delta as an example).

(iii) Integrated Transportation Convergence Development Level. There are 3 subindicators: road network density, which reflects the convergence situation between the logistics centers and the road network; white goods throughput in the main water ports, which shows development level of the international logistics; and the cargo throughput in the main airports, which reflects the convergence situation between the logistics centers and the regional aviation level.

(iv) The Related Policies. There are 3 subindicators. The first is administrative level, which is evaluated on the scale of $9,7,5$, 3 , or 1 . We use 9 to represent the municipality directly under the jurisdiction of the cities, 7 to represent the subprovincial cities, 5 to represent the general open cities, part of the provincial capital cities, or the border cities. We also use 3 to represent the prefecture-level cities and 1 for regional cities. The second subindicator is the level in the national logistics strategic planning. Usually, we take 3 to show the national first-level logistics center cities and to show the second-level central logistics cities, and the others take 0 . The last subindicator is the level in the National Strategic Planning. If the related National Strategic Planning existed in the regional under evaluation, we take 1; otherwise, we take 0 .

We collect initial data about the $j, j=1,2,3, \ldots, n$ second-class indicator during the $k, k=1,2,3, \ldots, m$ year; the initial data will be used as the inputs of the whole evaluation processes. For each second-class logistics area $i, u_{i, j}^{k}$ represents the collected value of the $j$ second-class indicator during the $k$ year.

\section{The Translation-Corrected Improved Entropy-Cloud Model: Formulation, Proof, and SSP Outputs}

4.1. The Translation-Corrected Improved Entropy Weight Method. In this paper, we use the translation-corrected entropy weight method to obtain the indicators' weight. The entropy weight method (EWM) is based on Shannon entropy, originally developed by Shannon and Weaver [31]. Shannon entropy is a concept which is proposed as a measure of uncertainty in information and formulated in terms of probability theory. The concept of entropy is well suited to measuring the relative intensities of contrast criteria in order to represent the average intrinsic information transmitted for decision-making [32]; then the method is applied to describe the thermodynamics information systems [33]. The EWM has already been applied to many research fields such as clinical neurophysiology [34], transport systems [35], environmental time series data, and conflict analysis [36, 37]. The uncertainty of signals in communication processes is called information entropy; the lower the information entropy, the higher the weight. The existing entropy weight method works as follows to calculate the weight.

The collected data about the subindicators mentioned in Section 2 can be formulated as a information decision matrix $A=\left[u_{i, j}^{k}\right]_{m \times n}$ and then calculate the initial decision matrix as standardizing decision matrix $R=\left[r_{i, j}^{k}\right]_{m \times n}$. There are two types of standardized methods: when the indicators are benefit-type, the calculation for normalization can be expressed as formula (1); if the indicators belong to cost-type, 
the calculation for normalization can be expressed as formula (2). From Section 3, we can find that all the subindicators belong to benefit-type, so all subindicators will be normalized by using the following:

$$
\begin{aligned}
& r_{i, j}^{k}=\frac{\left[u_{i, j}^{k}-\left(u_{i, j}^{k}\right)_{\min }\right]}{\left[\left(u_{i, j}^{k}\right)_{\max }-\left(u_{i, j}^{k}\right)_{\min }\right]}, \quad \forall i, j, k \\
& r_{i, j}^{k}=\frac{\left[\left(u_{i, j}^{k}\right)_{\max }-u_{i, j}^{k}\right]}{\left[\left(u_{i, j}^{k}\right)_{\max }-\left(u_{i, j}^{k}\right)_{\min }\right]}, \quad \forall i, j, k,
\end{aligned}
$$

where $r_{i, j}^{k}$ is the decision matrix after normalization, $\left(u_{i, j}^{k}\right)_{\max }$ is the maximum value of $u_{i, j}^{k}$, and $\left(u_{i, j}^{k}\right)_{\min }$ is the minimum value of $u_{i, j}^{k}$. If $\left(u_{i, j}^{k}\right)_{\max }=\left(u_{i, j}^{k}\right)_{\min }$, we let $r_{i, j}^{k}=0$ and then calculate the probability of each $u_{i, j}^{k}$ as follows:

$$
p_{i, j}^{k}=\frac{r_{i, j}^{k}}{\sum_{k=1}^{m} r_{i, j}^{k}}, \quad \forall i, j, k .
$$

The information entropy for each evaluation criteria $j$ is defined as follows:

$$
e_{i, j}=-\frac{1}{\ln m} \sum_{k=1}^{m} p_{i, j}^{k} \cdot \ln \left(p_{i, j}^{k}\right), \quad \forall i, j .
$$

And the weight obtained from information entropy for each evaluation criteria $j$ is expressed as follows:

$$
\omega_{i, j}=\frac{\left[1-e_{i, j}\right]}{\left[n-\sum_{j=1}^{n} e_{i, j}\right]}, \quad \forall i, j,
$$

where $0 \leq \omega_{i, j} \leq 1$ and $\sum_{j=1}^{n} \omega_{i, j}=1, \forall i$.

From the above EWM calculation formulas we can find that if the initial subindicator data has small fluctuation amplitude, or the data remains unchanged during the operation periods, which means, $\forall j$, for each $k$, the value $r_{i, j}^{k}=1$, or $r_{i, j}^{k}=0$, and

$$
1 \leq \sum_{k=1}^{m} r_{i, j}^{k}<m, \quad \forall j
$$

we use $\mathbb{R}$ to represent the condition mentioned above. If $j$ satisfies $\mathbb{R}$, then it shows this subindicator $j$ has no impact on the total HSR express freight train selection process and the evaluation will fail. In order to solve this problem, we corrected the existing EWM by adding a translation data into formula (3), detailed as follows:

$$
\begin{aligned}
p_{i, j}^{\prime k} & =\frac{\left[r_{i, j}^{k}+\Delta r_{i, j}^{k}\right]}{\left[\sum_{k=1}^{m}\left(r_{i, j}^{k}+\Delta r_{i, j}^{k}\right)\right]}, \quad \forall i, j, k \\
\Delta r_{i, j}^{k} & =\left\{\begin{array}{ll}
0, & 0<r_{i, j}^{k}<1 \\
0<\Delta r_{i, j}^{k}<1, & \mathbb{R}
\end{array}, \quad \forall i, j, k,\right.
\end{aligned}
$$

where $\Delta r_{i, j}^{k}$ is the translation value. After the translation correction in formula (7), some of the information contained in the existing data will be lost. In statistics, we can use the variance to measure the amount of information contained in a set of data. The variance of the data without translation will be larger than the corrected data. In order to maintain the integrity of the original data, the data information loss must be controlled in an acceptable range. For each evaluation criteria $j$, we assign Information Loss Tolerance Coefficient (ILTC) $\psi_{i, j}$ to restrict the information loss artificially. We next give the detailed reasoning, proof, and remarks about the properties.

Assuming there is a set of nonnegative numbers, $x_{1}, x_{2}$, $x_{3}, \ldots, x_{q}, \ldots, x_{Q}$, summation is $s=\sum_{q=1}^{\mathrm{Q}} x_{q}$. If the translation value is a constant $\Delta x, 0<\Delta x<1$, then summation after translation is $s^{\prime}=\sum_{q=1}^{Q}\left(x_{q}+\Delta x\right)=s+Q \cdot \Delta x$. After the calculation in formula (3) and formula (7), we can obtain two new sets of data, $y_{1}, y_{2}, y_{3}, \ldots, y_{q}, \ldots, y_{Q}$ and $y_{1}^{\prime}, y_{2}^{\prime}, y_{3}^{\prime}, \ldots, y_{q}^{\prime}, \ldots, y_{\mathrm{Q}}^{\prime}$. Then, we calculate the average number about the two sets of data, $\bar{y}_{q}=(1 / Q) \sum_{q=1}^{Q} y_{q}$ and $\bar{y}_{q}^{\prime}=(1 / Q) \sum_{q=1}^{Q} y_{q}^{\prime}$. The distribution of random variables $x_{q}, y_{q}, y_{q}^{\prime}$ can be formulated as follows:

$$
\begin{aligned}
p\left(x_{q}\right) & =p\left(y_{q}\right)=p\left(y_{q}^{\prime}\right)=\frac{1}{Q} \\
s^{2} & <(s+Q \cdot \Delta x)^{2} \Longleftrightarrow \\
{\left[\frac{\operatorname{var}\left(x_{q}\right)}{\left(s^{\prime}\right)^{2}}\right] } & <\left[\frac{\operatorname{var}\left(x_{q}\right)}{(s)^{2}}\right] \Longleftrightarrow \\
\operatorname{var}\left(y_{q}^{\prime}\right) & <\operatorname{var}\left(y_{q}\right) \\
\frac{\left[\sum_{q=1}^{Q}\left(y_{q}-\bar{y}_{q}\right)^{2}\right]}{(Q-1)} & >\frac{\left[\sum_{q=1}^{Q}\left(y_{q}^{\prime}-\bar{y}_{q}^{\prime}\right)^{2}\right]}{(Q-1)} .
\end{aligned}
$$

From formula (11) we can prove that the variance of the data without translation will be larger than the corrected data, which suggests that some information contained in the existing data is lost. We must control the initial data information loss in an acceptable range. $\psi_{i, j}$ will work as follows:

$$
\begin{aligned}
\frac{\sum_{q=1}^{\mathrm{Q}}\left(y_{q}^{\prime}-\bar{y}_{q}^{\prime}\right)^{2}}{\sum_{q=1}^{\mathrm{Q}}\left(y_{q}-\bar{y}_{q}\right)^{2}} \geq 1-\psi_{i, j} \Longleftrightarrow \frac{\operatorname{var}\left(y_{q}^{\prime}\right)}{\operatorname{var}\left(y_{q}\right)} \geq 1-\psi_{i, j} \\
\frac{\operatorname{var}\left(x_{q}\right) /(s+Q \cdot \Delta x)^{2}}{\operatorname{var}\left(x_{q}\right) / s^{2}} \geq 1-\psi_{i, j} \Longleftrightarrow \\
s^{2} \geq\left(1-\psi_{i, j}\right)(s+Q \cdot \Delta x)^{2} .
\end{aligned}
$$

According to formula (13), we can obtain the relationship among $\psi_{i, j}, Q, s, \Delta x$ using quadratic equation root function:

$$
0<\Delta x \leq \frac{s}{Q}\left(\frac{1}{\sqrt{1-\psi_{i, j}}}-1\right), \quad 0<\psi_{i, j}<1 .
$$


We establish a function to formulate the relationship among $\psi_{i, j}, Q, s, \Delta x$, where $\psi_{i, j}, Q, s$ are independent variables. $\Delta x$ belongs to dependent variable. The function is shown as follows:

$$
\Delta x\left(Q, s, \psi_{i, j}\right)=\frac{s}{Q}\left(\frac{1}{\sqrt{1-\psi_{i, j}}}-1\right) .
$$

Taken the derivative of each variable, we can obtain the following three constant established formulas:

$$
\begin{aligned}
& \frac{\partial \Delta x}{\partial Q}=\frac{s}{Q^{2}}\left(1-\frac{1}{\sqrt{1-\psi_{i, j}}}\right)<0 \\
& \frac{\partial \Delta x}{\partial s}=\frac{1}{Q}\left(\frac{1}{\sqrt{1-\psi_{i, j}}}-1\right)>0 \\
& \frac{\partial \Delta x}{\partial \eta}=\frac{s}{\left[2 Q \sqrt{\left(1-\psi_{i, j}\right)^{3}}\right]}>0 .
\end{aligned}
$$

The above three formulas (16) show that when the value of $s, \psi_{i, j}$ is fixed, the larger $Q$, the smaller $\Delta x$. When the value of $Q, \psi_{i, j}$ is fixed, the larger $s$, the larger $\Delta x$. When the value of $s, Q$ is fixed, the larger $\psi_{i, j}$, the larger $\Delta x$. In this paper, for the evaluation criteria $j$, we can control $\Delta r_{i, j}^{k}$ in a reasonable range by setting $\psi_{i, j}$ in an acceptable range, artificially. After the process, the data information loss can be controlled in a reasonable range. The inherent defects of the entropy weight method can be restrained to a certain extent and make all indicators play a role in the evaluation processes.

4.2. The Cloud Theory and Cloud Model. Cloud theory was first delimited and applied by Li et al. [38]. Cloud model (CM) can synthetically describe the randomness and fuzziness of qualitative information and implement uncertain transformations between qualitative information and its quantitative instantiations based on probability statistics and fuzzy set theory. Usually the CM uses the forward cloud transformation (FCT) and the backward cloud transformation (BCT) to implement the cognitive transformations, which can reduce greatly loss of information. Now it has been used extensively in many fields such as natural language processing, data mining, decision analysis, intelligent control, and image processing. Li et al. [39] used CM to evaluate the smart distribution grid; the evaluation model included two parts: synthesized cloud and remarks cloud, and the final evaluation results are given in the form of probability distribution. Also, Fan et al. [40] applied the improved evaluation method based on CM for situation consistency within the battlefield of joint operations. The improved assessment approach is based on Cloud Gravity Centre Theory and uses Structure Entropy Weight to calculate the weight of the indexes. Furthermore, the CM has also been used for risk management, for example, Zhang et al. [41], Li et al. [42], and Zhang et al. [43], and route assessment; see $\mathrm{Ma}$ and $\mathrm{Xu}$ [44]. Wu et al. [45] proposed a cloud-based decision framework to solve the waste-to-energy plant site selection problem (SSP). Deng et al. [46] combined Heuristic Gaussian cloud transformation and fuzzy forecasting method to solve the novel hybrid water quality time series prediction problem. Some of the recent papers have been also devoted to the development of CM theoretical research. Wang et al. [47] proposed a linguistic multicriteria group decision-making method based on three kinds of cloud aggregation operators, that is, cloud weighted arithmetic averaging operator, cloud-ordered weighted arithmetic averaging operator, and cloud hybrid arithmetic operator. Also, Wang et al. [48] used CM to solve the uncertain linguistic multicriteria group decision-making problem. Wang et al. [49] established a generic normal cloud model and then designed and compared some algorithms to solve the model, which included 2nd2nd-order generic normal cloud model (2nd2nd-GFCT), 2nd2nd-order generic forward normal cloud transformation algorithm (2nd2ndGIBCT), 2nd2nd-order generic backward cloud transformation algorithm (2nd2nd-GBCT), pthpth-order generic forward normal cloud transformation algorithm (pthpthGFCT), and the backward cloud transformation algorithm (pthpth-GBCT). Wu et al. [50] proposed a new model, which combined the normal cloud model (CM) and Fruit Fly Optimization Algorithm (FOA), to solve the problem.

According to the previous research results, the digital signature of clouds reflects the quantitative characteristics about the qualitative concept. For each second-class logistics area $i$ and each second-class indicator $j, j=1,2, \ldots, n$, $n \in N^{+}$, we use three kinds of values to formulate a cloud, including Expectation Value $E_{X}^{i, j}$, Entropy Value $E_{N}^{i, j}$, and Super Entropy Value $H_{E}^{i, j} \cdot E_{X}^{i, j}$ represents the average point of the cloud drops group. $E_{N}^{i, j}$ shows the fuzziness and randomness in the qualitative concept and represents the acceptable range of concept in the domain. $H_{E}^{i, j}$ is the uncertainty measurement of Entropy Value $E_{N}^{i, j}$ or, more specifically, the entropy of the Entropy Value $E_{N}^{i, j}$, which represents the condensation degree of the cloud drops group. Smaller $H_{E}^{i, j}$ value implies a better condensation degree of the cloud drops group, lower measures of dispersion, and thinner thickness of the cloud. The three basic values used to formulate the CM are shown in Figure 2(a). If we use $G$ as the quantitative characteristics with exact value, $T^{i, j}$ is the qualitative concept; then

$$
T^{i, j}=G\left(E_{X}^{i, j}, E_{N}^{i, j}, H_{E}^{i, j}\right), \quad \forall i, j .
$$

So, the evaluation process for each station based on CM works as follows.

Step 1. We use Expert Scoring Method to obtain the basic evaluation criteria cloud.

All the second-class logistics areas have three handling alternatives: renovate and develop as a LC, or LB, or the second-class logistics area has no HSR logistics business to handle (referred to as $N$ ). Each kind of alternative is 


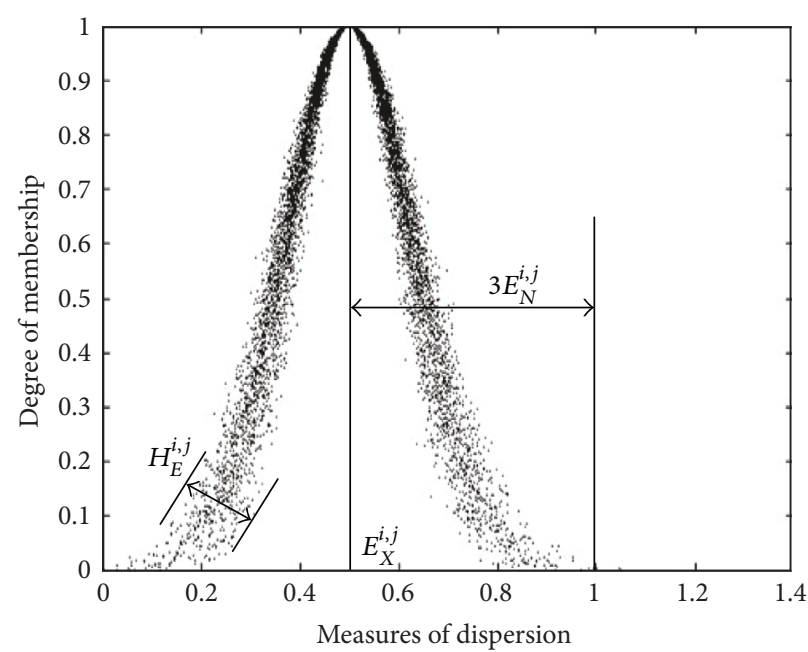

(a) The three basic values to formulate $\mathrm{CM}$

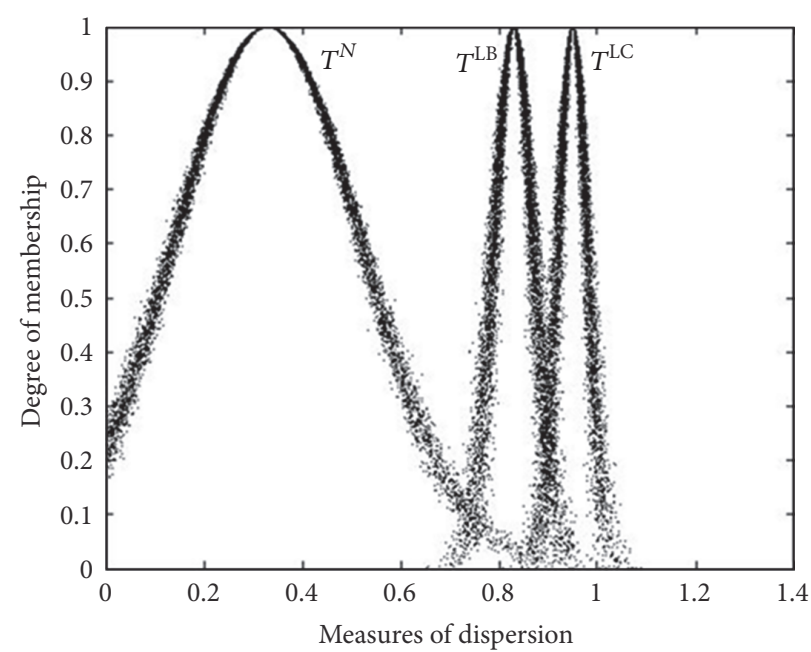

(b) The three basic evaluation clouds

Figure 2: Basic elements of CM applied in this paper.

formulated by a basic visualization evaluation cloud. We use ESM together with MATLAB to control the convergence speed and quality of expertise, and the final visualization evaluation clouds must meet the overall national strategic planning, such as the number limitation for each kind of station. The three basic evaluation clouds $T^{\mathrm{LC}}, T^{\mathrm{LB}}, T^{N}$ will be used as criteria during the final evaluation process; please refer to formula (21)-(24) to get the core calculation steps. Three basic evaluation clouds were visualized in Figure 2(b).

$$
\begin{aligned}
& T^{\mathrm{LC}}=G\left(E_{X}^{\mathrm{LC}}, E_{N}^{\mathrm{LC}}, H_{E}^{\mathrm{LC}}\right) \\
& T^{\mathrm{LB}}=G\left(E_{X}^{\mathrm{LB}}, E_{N}^{\mathrm{LB}}, H_{E}^{\mathrm{LB}}\right) \\
& T^{N}=G\left(E_{X}^{N}, E_{N}^{N}, H_{E}^{N}\right) .
\end{aligned}
$$

Step 2. For each second-class logistics area $i$ and second-class indicator $j$, use the obtained standardizing decision matrix $R=\left[r_{i, j}^{k}\right]_{m \times n}$ to do the following calculation. Firstly, calculate the sample mean $E_{X}^{i, j}$ and sample variance $\left(S^{i, j}\right)^{2}$, respectively.

$$
\begin{aligned}
E_{X}^{i, j} & =\frac{1}{m} \times \sum_{k=1}^{m} r_{i, j}^{k}, \quad \forall i, j \\
\left(S^{i, j}\right)^{2} & =\frac{1}{m-1} \times \sum_{k=1}^{m}\left(r_{i, j}^{k}-E_{X}^{i, j}\right)^{2}, \quad \forall i, j .
\end{aligned}
$$

Then we can obtain the Entropy Value $E_{N}^{i, j}$ and Super Entropy Value $H_{E}^{i, j}$ based on the sample mean and sample variance.

$$
\begin{aligned}
& E_{N}^{i, j}=\sqrt{\frac{\pi}{2}} \times \frac{1}{m} \times \sum_{k=1}^{m}\left|r_{i, j}^{k}-E_{X}^{i, j}\right|, \quad \forall i, j \\
& H_{E}^{i, j}=\sqrt{\left(S^{i, j}\right)^{2}-\left(E_{N}^{i, j}\right)^{2}}, \quad \forall i, j .
\end{aligned}
$$

4.3. The SSP Outputs. For each second-class logistics area $i$ under evaluation, to obtain the final evaluation cloud $T^{i}$, we use the weight $\omega_{i, j}$ to multiply the initial evaluation cloud $T^{i, j}$.

$$
\begin{aligned}
& T^{i}=\sum_{j=1}^{n}{\aleph_{i, j}} \times T^{i, j}, \quad \forall i \\
& T^{i}=G\left(E_{X}^{i}, E_{N}^{i}, H_{E}^{i}\right), \quad \forall i .
\end{aligned}
$$

Use MATLAB to obtain the visible $T^{i}, T^{\mathrm{LC}}, T^{\mathrm{LB}}$, and $T^{N}$ in the same interface and compare the four figures: the evaluated second-class logistics area $i$ belongs to one of the alternatives $\left(T^{\mathrm{LC}}, T^{\mathrm{LB}}\right.$, or $\left.T^{N}\right)$ if $T^{i}$ is closer to one of the figures. Also, we can use the following evaluation method to obtain the final result, adjunctively.

$$
T^{i}=\min \left\{\left|E_{X}^{\mathrm{LC}}-E_{X}^{i}\right|,\left|E_{X}^{\mathrm{LB}}-E_{X}^{i}\right|,\left|E_{X}^{N}-E_{X}^{i}\right|\right\}, \quad \forall i .
$$

The detailed circuit to solve the HSR express train SSP is presented in Figure 3.

\section{Case Study: Comparison Analysis and Results Discussions}

We now give our case study by taking the Yangtze River Delta first-class logistics area in China as a background. Yangtze River Delta is one of the most developed logistics area in China, with an area of $354,400 \mathrm{~km}^{2}$ and a total population of 227 million. It consists of the three provinces of Anhui, Jiangsu, and Zhejiang, with Shanghai as the center of economic activities. In addition to the main city of Shanghai, there are a number of regional central cities, such as Hangzhou and Nanjing. Other cities such as Wenzhou, Ningbo, Wuxi, and Suzhou are also highly developed. With the completion of the Hefei-Nanjing Passenger Railway (the first HSR in the Yangtze River Delta) in 2008, 24 out of 


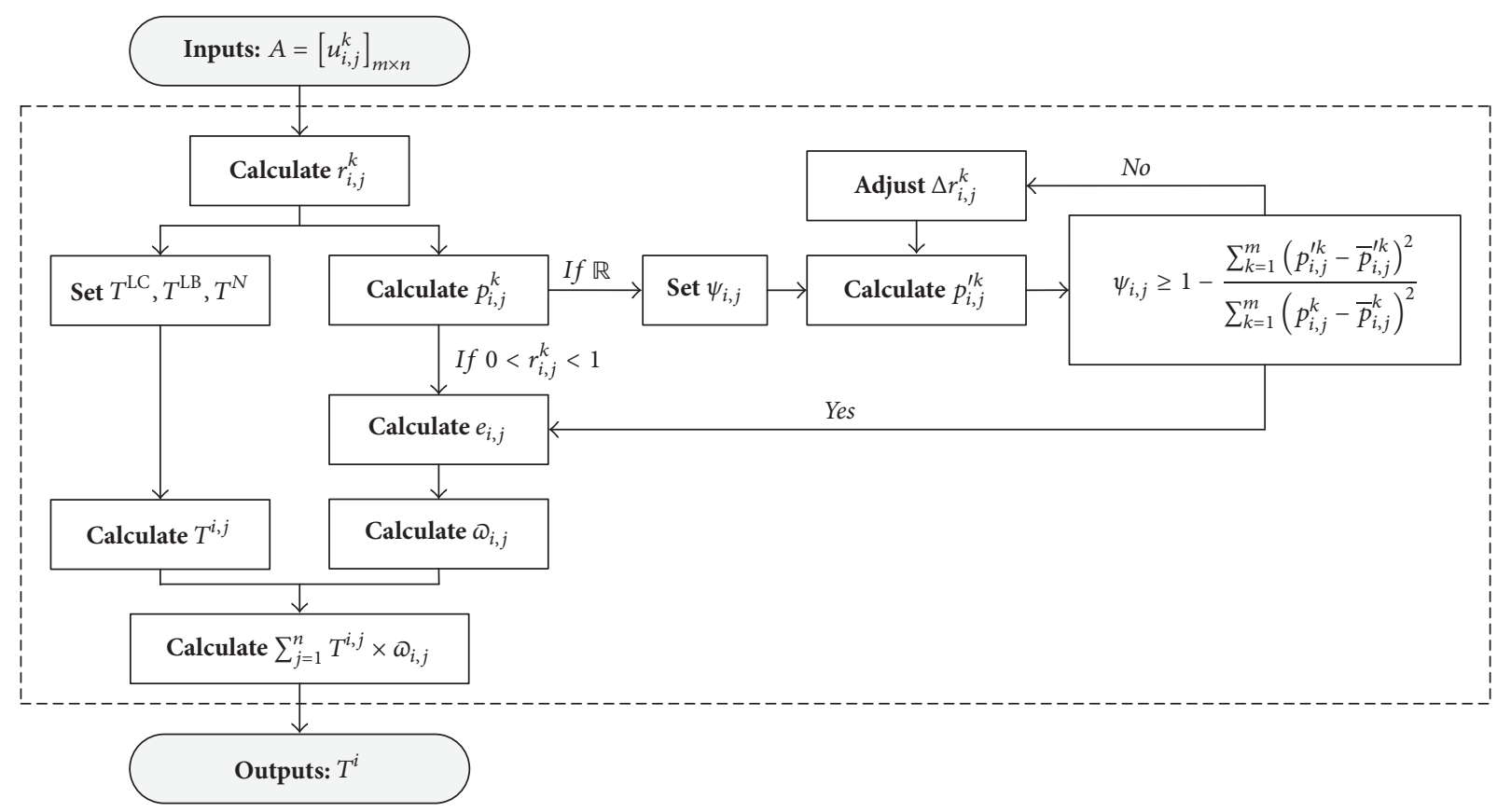

FIGURE 3: Detailed circuit to solve the HSR express train SSP.

39 cities were accessible by HSR in the Yangtze River Delta by 2014 [51]. The highly developed HSR networks not only reduce the passenger travel time between cities but also provide good foundation for the development of HSR express freight train services. In order to select the LCs and LBs, we divided the Yangtze River Delta into 13 second-class logistics areas, shown in Figure 1. For each second-class logistics area $i$, we collected the initial data of the 15 subindicators from 2008 to 2015 and formed an information decision matrix $A=\left[u_{i, j}^{k}\right]_{8 \times 15}$. The initial matrix of the 13 second-class logistics areas will not be presented in this paper because of its huge scale; for detailed information please see China Railway Corporation and Southwest Jiaotong University [52]; all the used data was obtained from National Statistics Bureau of the People's Republic of China [53], Ministry of Transport of the People's Republic of China [54], and Ministry of Commerce of the People's Republic of China [55]. Next we presented the weight for each subindicator of the second-class logistics areas based on improved entropy method and the HSR freight train service site selection results.

5.1. The Weight. For the Yangtze River Delta logistics area, some subindicators such as administrative level and level in the national logistics strategic planning remained unchanged during 2008 to 2015, so these two subindicators need to be translation-corrected. In order to compare the difference of final weight under different ILTC $\psi_{i, j}$, we took the Shanghai second-class logistics area as an example. We let $\psi_{i, j}=$ $0.2,0.15,0.1,0.05$, and 0.01 , calculated the translation value according to formula (14), and obtained the value ranges. We used the maximum of $\Delta r_{i, j}^{k}$ in this paper. The weight $\omega_{i, j}$ under each $\psi_{i, j}$ is presented in Table 1.
From Table 1 we can find that the smaller $\psi_{i, j}$ is, the closer the final weight $\Phi_{i, j}$ is to the weight without translationcorrected $\left(\psi_{i, j}=0\right)$. So, if we want to control the data information loss in a reasonable range, we should set $\psi_{i, j}$ in a sufficiently small range so that the inherent defects of the entropy weight method can be restrained to a certain extent and make all indicators play a role in the weight obtaining processes. Therefore, we set the ILTC $\psi_{i, j}=0.01$ for the other 12 second-class logistics areas, and the final weights for each subindicator of the 13 second-class logistics areas are as presented in Table 2.

From Table 2 we can find the following. (i) For the development of HSR logistics in the Yangtze River Delta area, the related policies are not the most important influencing factors. (ii) The key influencing factors are GDP, total retail sales of social consumer goods, HSR operational line length, and road network density, because the weight values of the four subindicators are larger than the others.

5.2. The Selection Results. To satisfy the basic national strategic planning of the HSR freight train service sites selection, we invited 10 experts (including 5 Professors and 1 Associate Professor from School of Transportation and Logistics, Southwest Jiaotong University, and 4 Senior Engineers from China Railway Siyuan Survey and Design Group Co. Ltd.; all experts' specialization is railway operation network planning and design) to evaluate and score for the three kinds of criteria. After transferring the scoring value into evaluation values $E_{X}^{i, j}, E_{N}^{i, j}$, and $H_{E}^{i, j}$, we used MATLAB to make the clouds visual. The final evaluation clouds criteria are $T^{\mathrm{LC}}=G(0.93,0.03,0.006), T^{\mathrm{LB}}=G(0.85,0.04,0.007)$, $T^{N}=G(0.33,0.20,0.008)$, shown in Figure $2(\mathrm{~b})$, which is 
TABLE 1: The weight $\varpi_{i, j}$ under each $\psi_{i, j}$ (the Shanghai second-class logistics area case).

\begin{tabular}{|c|c|c|c|c|c|c|}
\hline$\Phi_{i, j}$ & $\psi_{i, j}=0.20$ & $\psi_{i, j}=0.15$ & $\psi_{i, j}=0.10$ & $\psi_{i, j}=0.05$ & $\psi_{i, j}=0.01$ & $\psi_{i, j}=0$ \\
\hline 1 & 0.105 & 0.103 & 0.102 & 0.100 & 0.099 & 0.099 \\
\hline 2 & 0.078 & 0.077 & 0.076 & 0.075 & 0.074 & 0.074 \\
\hline 3 & 0.082 & 0.090 & 0.078 & 0.088 & 0.087 & 0.087 \\
\hline 4 & 0.082 & 0.081 & 0.080 & 0.079 & 0.078 & 0.078 \\
\hline 5 & 0.087 & 0.095 & 0.095 & 0.093 & 0.092 & 0.092 \\
\hline 6 & 0.092 & 0.090 & 0.089 & 0.088 & 0.087 & 0.086 \\
\hline 7 & 0.089 & 0.088 & 0.087 & 0.086 & 0.085 & 0.084 \\
\hline 8 & 0.068 & 0.068 & 0.066 & 0.065 & 0.064 & 0.063 \\
\hline 9 & 0.083 & 0.068 & 0.090 & 0.088 & 0.088 & 0.088 \\
\hline 10 & 0.082 & 0.078 & 0.076 & 0.071 & 0.078 & 0.078 \\
\hline 11 & 0.073 & 0.087 & 0.086 & 0.085 & 0.084 & 0.084 \\
\hline 12 & 0.064 & 0.059 & 0.061 & 0.069 & 0.071 & 0.072 \\
\hline 13 & 0.005 & 0.005 & 0.005 & 0.005 & 0.005 & 0.006 \\
\hline 14 & 0.006 & 0.007 & 0.006 & 0.005 & 0.006 & 0.007 \\
\hline 15 & 0.004 & 0.004 & 0.003 & 0.003 & 0.002 & 0.002 \\
\hline
\end{tabular}

TABLE 2: Weights for each subindicator of the 13 second-class logistics areas (the Yangtze River Delta case).

\begin{tabular}{lcccccccccccccc}
\hline$\omega_{i, j}$ & SH & NZ & SZ & EZ & WZ & SJ & CJ & NJ & CA & EA & WA & NA & SA \\
\hline 1 & 0.099 & 0.094 & 0.084 & 0.084 & 0.087 & 0.087 & 0.079 & 0.081 & 0.084 & 0.079 & 0.085 & 0.084 & 0.079 \\
2 & 0.074 & 0.089 & 0.074 & 0.081 & 0.057 & 0.088 & 0.081 & 0.057 & 0.088 & 0.077 & 0.075 & 0.086 & 0.077 \\
3 & 0.087 & 0.074 & 0.061 & 0.052 & 0.059 & 0.075 & 0.059 & 0.055 & 0.089 & 0.089 & 0.069 & 0.079 & 0.084 \\
4 & 0.078 & 0.056 & 0.079 & 0.067 & 0.075 & 0.086 & 0.072 & 0.089 & 0.087 & 0.087 & 0.085 & 0.084 & 0.085 \\
5 & 0.092 & 0.077 & 0.098 & 0.047 & 0.094 & 0.084 & 0.082 & 0.078 & 0.088 & 0.079 & 0.087 & 0.059 & 0.086 \\
6 & 0.087 & 0.078 & 0.073 & 0.087 & 0.089 & 0.074 & 0.099 & 0.091 & 0.088 & 0.091 & 0.094 & 0.098 & 0.089 \\
7 & 0.085 & 0.095 & 0.097 & 0.099 & 0.097 & 0.099 & 0.091 & 0.095 & 0.077 & 0.091 & 0.066 & 0.094 & 0.096 \\
8 & 0.064 & 0.081 & 0.087 & 0.098 & 0.145 & 0.083 & 0.077 & 0.098 & 0.074 & 0.107 & 0.106 & 0.137 & 0.107 \\
9 & 0.088 & 0.074 & 0.098 & 0.097 & 0.094 & 0.076 & 0.085 & 0.099 & 0.075 & 0.092 & 0.098 & 0.114 & 0.094 \\
10 & 0.078 & 0.089 & 0.078 & 0.094 & 0.084 & 0.088 & 0.085 & 0.076 & 0.074 & 0.097 & 0.095 & 0.097 & 0.095 \\
11 & 0.084 & 0.088 & 0.092 & 0.091 & 0.053 & 0.077 & 0.097 & 0.076 & 0.076 & 0.049 & 0.094 & 0.059 & 0.021 \\
12 & 0.071 & 0.094 & 0.071 & 0.093 & 0.058 & 0.072 & 0.084 & 0.097 & 0.089 & 0.054 & 0.038 & 0.001 & 0.079 \\
13 & 0.005 & 0.004 & 0.003 & 0.003 & 0.003 & 0.004 & 0.003 & 0.003 & 0.004 & 0.003 & 0.003 & 0.003 & 0.003 \\
14 & 0.007 & 0.006 & 0.004 & 0.006 & 0.004 & 0.006 & 0.005 & 0.004 & 0.006 & 0.004 & 0.004 & 0.004 & 0.004 \\
15 & 0.001 & 0.001 & 0.001 & 0.001 & 0.001 & 0.001 & 0.001 & 0.001 & 0.001 & 0.001 & 0.001 & 0.001 & 0.001 \\
\hline
\end{tabular}

SH: Shanghai; NZ: North Zhejiang; for other abbreviations please see Figure 1.

the output of the 10 experts' evaluation and scoring. For each subindicator of the second-class logistics area, we can obtain an evaluation cloud. In this paper, we only presented (shown in Table 3) four second-class logistics areas' clouds (including $1 \mathrm{LC}$ and $3 \mathrm{LBs}$ ) because of the data's huge scale.

According to the formulas (26)-(27), we multiplied the weight in Table 2 and evaluation clouds in Table 3 and obtained the final evaluation cloud $T^{i}$ for each second-class logistics area $i$. Next, we used MATLAB to make the clouds $T^{i}$ visual and compared $T^{i}$ with $T^{\mathrm{LC}}, T^{\mathrm{LB}}$, and $T^{N}$ (also we can use the formula 30). The final results are presented in Table 4 and Figure 4.

South Jiangsu (SJ) was selected as the HSRELC (red cloud in Figure 4) with Nanjing chosen as the location city. Shanghai (SH), North Zhejiang (NZ), and Central Anhui (CA) were selected as HSRELBs (yellow clouds in Figure 4), with Shanghai, Hangzhou, and Hefei chosen as the location cities, respectively. The other 9 second-class logistics areas have no HSR freight train service (blue clouds in Figure 4).

Meanwhile, we can apply the same approach to obtain the HSR freight train service sites for other 7 first-class logistics areas, including Pearl River Delta, North China, Northeast China, Bohai logistics area, Central China, Southwest China, and Northwest China. The 8 LCs, 23 LBs, and the collected HSR railway lines formed the basic freight train service network in China as shown in Figure 5.

\section{Conclusion and Further Study Works}

The High-Speed Railway (HSR) express freight train service belongs to an emerging transport product, which is the most important approach for China railway to obtain more 

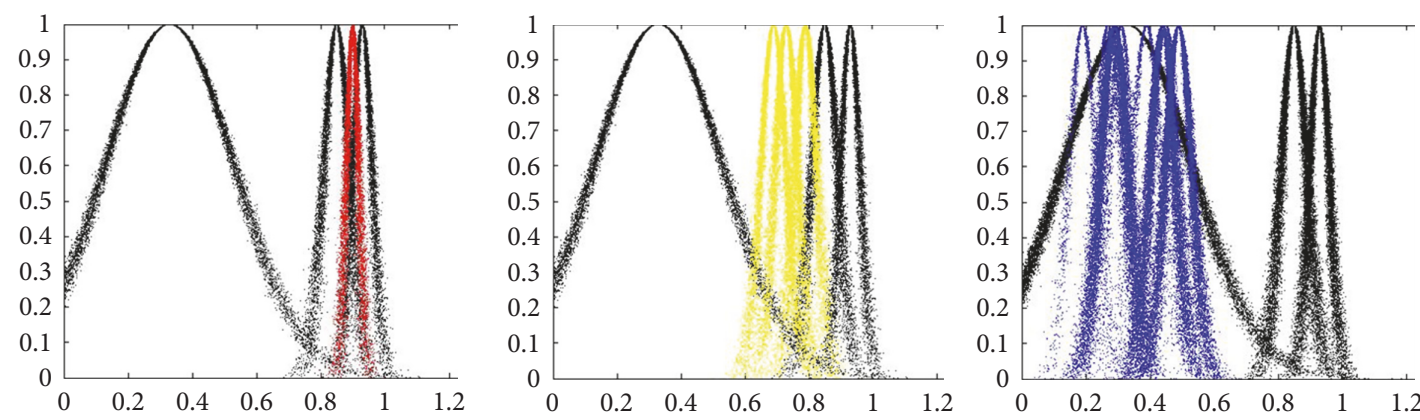

FIgURE 4: The visual results of the 13 second-class logistics areas in the Yangtze River Delta area.

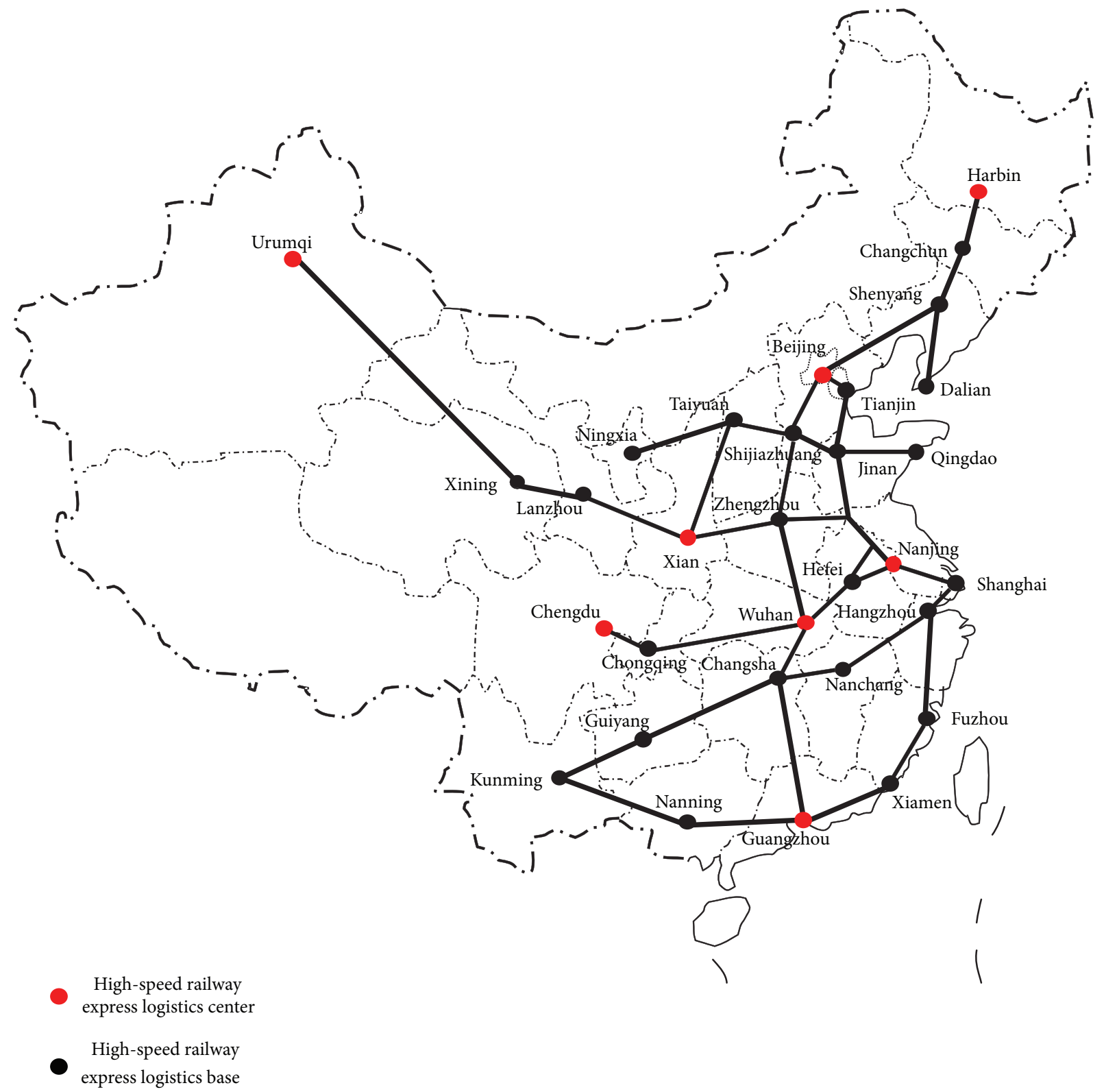

Figure 5: The HSR freight train service network in China. 
TABLE 3: The evaluation cloud for each subindicator of SH, SJ, NZ, and CA.

\begin{tabular}{lcccr}
\hline & SH & SJ & NZ & CA \\
\hline 1 & $(0.89,0.024,0.008)$ & $(0.96,0.012,0.005)$ & $(0.59,0.036,0.008)$ & $(0.68,0.044,0.008)$ \\
2 & $(0.79,0.045,0.007)$ & $(0.99,0.019,0.009)$ & $(0.89,0.045,0.008)$ & $(0.69,0.036,0.007)$ \\
3 & $(0.88,0.029,0.009)$ & $(0.85,0.017,0.008)$ & $(0.75,0.047,0.007)$ & $(0.67,0.039,0.007)$ \\
4 & $(0.96,0.036,0.009)$ & $(0.92,0.011,0.004)$ & $(0.74,0.042,0.009)$ & $(0.79,0.035,0.007)$ \\
5 & $(0.92,0.045,0.009)$ & $(0.95,0.012,0.006)$ & $(0.76,0.036,0.008)$ & $(0.78,0.031,0.009)$ \\
6 & $(0.82,0.047,0.006)$ & $(0.89,0.026,0.008)$ & $(0.56,0.034,0.006)$ & $(0.88,0.046,0.006)$ \\
7 & $(0.84,0.055,0.005)$ & $(0.79,0.025,0.007)$ & $(0.69,0.035,0.005)$ & $(0.84,0.048,0.005)$ \\
8 & $(0.67,0.016,0.008)$ & $(0.84,0.027,0.006)$ & $(0.68,0.042,0.004)$ & $(0.73,0.027,0.005)$ \\
9 & $(0.59,0.029,0.007)$ & $(0.96,0.029,0.008)$ & $(0.88,0.041,0.006)$ & $(0.71,0.022,0.007)$ \\
10 & $(0.68,0.025,0.009)$ & $(0.93,0.014,0.004)$ & $(0.75,0.044,0.008)$ & $(0.69,0.029,0.008)$ \\
11 & $(0.59,0.024,0.007)$ & $(0.97,0.025,0.002)$ & $(0.46,0.036,0.007)$ & $(0.59,0.027,0.006)$ \\
12 & $(0.88,0.031,0.008)$ & $(0.81,0.016,0.006)$ & $(0.69,0.037,0.005)$ & $(0.68,0.036,0.006)$ \\
13 & $(0.84,0.019,0.005)$ & $(0.85,0.024,0.002)$ & $(0.58,0.029,0.004)$ & $(0.69,0.037,0.005)$ \\
14 & $(0.89,0.028,0.006)$ & $(0.86,0.019,0.007)$ & $(0.79,0.027,0.004)$ & $(0.69,0.048,0.008)$ \\
15 & $(0.13,0.023,0.003)$ & $(0.13,0.023,0.003)$ & $(0.13,0.023,0.003)$ & $(0.13,0.023,0.003)$ \\
\hline
\end{tabular}

SH: Shanghai; NZ: North Zhejiang; for other abbreviations please see Figure 1.

TABLE 4: The final evaluation clouds of the 13 second-class logistics areas in the Yangtze River Delta area.

\begin{tabular}{lccc}
\hline & $T^{i}$ & Results & City \\
\hline SH & $(0.79,0.034,0.008)$ & LB & Shanghai \\
NZ & $(0.69,0.039,0.006)$ & LB & Hangzhou \\
SZ & $(0.49,0.041,0.007)$ & $\mathrm{N}$ & $\times$ \\
EZ & $(0.44,0.039,0.008)$ & $\mathrm{N}$ & $\times$ \\
WZ & $(0.39,0.047,0.008)$ & $\mathrm{N}$ & $\times$ \\
SJ & $(0.90,0.019,0.006)$ & $\mathrm{LC}$ & Nanjing \\
CJ & $(0.29,0.043,0.008)$ & $\mathrm{N}$ & $\times$ \\
NJ & $(0.45,0.044,0.007)$ & $\mathrm{N}$ & $\times$ \\
CA & $(0.73,0.035,0.007)$ & $\mathrm{LB}$ & Hefei \\
EA & $(0.27,0.041,0.008)$ & $\mathrm{N}$ & $\times$ \\
WA & $(0.19,0.042,0.007)$ & $\mathrm{N}$ & $\times$ \\
NA & $(0.28,0.038,0.006)$ & $\mathrm{N}$ & $\times$ \\
SA & $(0.31,0.036,0.008)$ & $\mathrm{N}$ & $\times$ \\
- & - & - & - \\
\hline
\end{tabular}

SH: Shanghai; NZ: North Zhejiang; for other abbreviations please see Figure 1.

market shares in high value-added goods transportation. HSR express freight train service sites selection problem is the basic Strategic Planning problem. The service sites are selected and developed based on the existing HSR railway stations, including high-speed railway express logistics centers (LC), high-speed railway express logistics bases (LB), or no TPL service. In this paper we formulated a new approach based on improved entropy-cloud model (IECM) to solve the HSR express sites selection problem (SSP). It has certain theoretical and practical significance to improve the utilization efficiency of high-speed railway, enhance railway image, and increase railway income.

First, we divided the whole China into 8 first-class logistics areas, including Pearl River Delta, Yangtze River Delta,
North China, Northeast China, Bohai logistics area, Central China, Southwest China, and Northwest China. Then, we divided each first-class logistics area into several second-class logistics areas, because different first-class logistics area and second-class logistics areas have different economic development and HSR operated lines length. Next, we established the HSR express freight train service sites selection evaluation system, including 4 first-class indicators and 15 second-class indicators; the collected basic data of the evaluation system was used as the inputs of the whole sites selection process.

There are two parts for the sites selection processes. First, we obtained the weight of each subindicator based on translation-corrected improved entropy weight method. The mathematical proof and the Shanghai case study results showed that the smaller $\psi_{i, j}$ is, the closer final weight $\omega_{i, j}$ is to the weight without translation correction. So, if we want to control the data information loss in a reasonable range, we should set the ILTC in a sufficiently small range so that the inherent defects of the entropy weight method can be restrained to a certain extent and make all indicators play a role in the weight obtaining processes. Second, we applied the cloud model (CM) to obtain the evaluation cloud for each subindicator. We used the weight to multiply the initial evaluation cloud, and the resulting outputs were presented visually for easy comparison and final selection.

We next gave our case study taking the Yangtze River Delta first-class logistics area in China as a background. In order to select the LCs and LBs, we divided the Yangtze River Delta into 13 second-class logistics areas. For each second-class logistics area $i$, we collected the initial data of the 15 subindicators from 2008 to 2015 . We selected the South Jiangsu as the LC with Nanjing chosen as the location city. Shanghai, North Zhejiang, and Central Anhui were selected as LBs with Shanghai, Hangzhou, and Hefei chosen as the location cities, respectively. The other 9 second-class logistics areas have no HSR freight train service. Meanwhile, we applied the same approach to obtain the HSR freight train 
service sites for other 7 first-class logistics areas resulting in 8 LCs, 23 LBs, and the collective HSR railway lines forming the basic freight train service network in China.

The proposed new site selection approach is also suitable for other related problems, but the evaluation indicators may be different. So, how to apply this approach into actual engineering practice and how to determine the ILTC, as well as the value of $\Delta r_{i, j}^{k}$ reasonably in the practice, are further study works.

\section{Conflicts of Interest}

The authors declare that there are no conflicts of interest regarding the publication of this paper.

\section{Acknowledgments}

This research was jointly supported by the Traffic and Transportation Engineering Experiment and Comprehensive Innovation Center, School of Transportation and Logistics, Southwest Jiaotong University, Chengdu, Sichuan, and subsidized by the National Natural Science Foundation of China (71173177), China State Railway Administration of Science and Technology Legal Division (KF2013-020), and the Southwest Jiaotong University 2015 Graduate Innovative Experimental Practice Program (YC201507103).

\section{References}

[1] S.-J. Jeong, C.-G. Lee, and J. H. Bookbinder, "The European freight railway system as a hub-and-spoke network," Transportation Research Part A: Policy and Practice, vol. 41, no. 6, pp. 523-536, 2007.

[2] S. Alumur and B. Y. Kara, "Network hub location problems: the state of the art," European Journal of Operational Research, vol. 190, no. 1, pp. 1-21, 2008.

[3] Q. Meng and X. Wang, "Intermodal hub-and-spoke network design: incorporating multiple stakeholders and multi-type containers," Transportation Research Part B: Methodological, vol. 45, no. 4, pp. 724-742, 2011.

[4] S. A. Alumur, B. Y. Kara, and O. E. Karasan, "Multimodal hub location and hub network design," Omega, vol. 40, no. 6, pp. 927-939, 2012.

[5] K. Yang, L. Yang, and Z. Gao, "Planning and optimization of intermodal hub-and-spoke network under mixed uncertainty," Transportation Research Part E: Logistics and Transportation Review, vol. 95, pp. 248-266, 2016.

[6] E. Z. Serper and S. A. Alumur, "The design of capacitated intermodal hub networks with different vehicle types," Transportation Research Part B: Methodological, vol. 86, pp. 51-65, 2016.

[7] M. E. O'Kelly, "A quadratic integer program for the location of interacting hub facilities," European Journal of Operational Research, vol. 32, no. 3, pp. 393-404, 1987.

[8] J. F. Campbell, "Integer programming formulations of discrete hub location problems," European Journal of Operational Research, vol. 72, no. 2, pp. 387-405, 1994.

[9] J. F. Campbell, "Hub location and the $p$-hub median problem," Operations Research, vol. 44, no. 6, pp. 923-935, 1996.

[10] D. Skorin-Kapov, J. Skorin-Kapov, and M. O’Kelly, “Tight linear programming relaxations of uncapacitated $\mathrm{p}$-hub median problems," European Journal of Operational Research, vol. 94, no. 3, pp. 582-593, 1996.

[11] J. G. Klincewicz, "Hub location in backbone/tributary network design: a review," Location Science, vol. 6, no. 1-4, pp. 307-335, 1998.

[12] H. Podnar, J. Skorin-Kapov, and D. Skorin-Kapov, "Network cost minimization using threshold-based discounting," European Journal of Operational Research, vol. 137, no. 2, pp. 371-386, 2002.

[13] A. T. Ernst and M. Krishnamoorthy, "Exact and heuristic algorithms for the uncapacitated multiple allocation p-hub median problem," European Journal of Operational Research, vol. 104, no. 1, pp. 100-112, 1998.

[14] J. Ebery, M. Krishnamoorthy, A. Ernst, and N. Boland, "Capacitated multiple allocation hub location problem: Formulations and algorithms," European Journal of Operational Research, vol. 120 , no. 3, pp. 614-631, 2000.

[15] N. Boland, M. Krishnamoorthy, A. . Ernst, and J. Ebery, "Preprocessing and cutting for multiple allocation hub location problems," European Journal of Operational Research, vol. 155, no. 3, pp. 638-653, 2004.

[16] F. Hai, X. Yan, C. Ding, and X. Shao, "Nodes selection of regional logistics network based on hub-and-spoke theory," Jisuanji Jicheng Zhizao Xitong/Computer Integrated Manufacturing Systems, CIMS, vol. 18, no. 6, pp. 1299-1305, 2012.

[17] H. T. Sun and Z. Q. Li, "Fuzzy Cluster Analysis on Railway Logistics Node Planning," Computer Technology and Development, vol. 24, no. 3, pp. 54-57, 2014.

[18] L. X. Huang, B. Shuai, and W. X. Wang, "Optimization of huband-spoke service network design for railway express freight train," Application Research of Computers, vol. 32, no. 7, pp. 19741978, 2015.

[19] C. Z. Yin, L. Bu, X. Q. Chen, and Y. Pu, "Model for location planning problem on railway baggage and parcel logistics base and distribution sites with uncertain demand," Systems Engineering, vol. 24, no. 1, pp. 53-57, 2006.

[20] C.-Z. Yin, L. Bu, and X.-Q. Cheng, "Study on the location plan for logistics base and distribution sites of railway baggage and parcel," Zhongguo Tiedao Kexue/China Railway Science, vol. 27, no. 3, pp. 116-120, 2006.

[21] C.-Z. Yin, L. Bu, X.-Q. Cheng, and Y. Pu, “Tabu search algorithm on location for railway baggage and parcel base and distribution sites," Kongzhi yu Juece/Control and Decision, vol. 21, no. 11, pp. 1316-1320, 2006.

[22] N. Mohajeri and G. R. Amin, "Railway station site selection using analytical hierarchy process and data envelopment analysis," Computers \& Industrial Engineering, vol. 59, no. 1, pp. 107$114,2010$.

[23] C. Bersani, C. Guerisoli, N. Mazzino, R. Sacile, and M. Sallak, "A multi-criteria methodology to evaluate the optimal location of a multifunctional railway portal on the railway network," Journal of Rail Transport Planning and Management, vol. 5, no. 2, pp. 78-91, 2015.

[24] A. Ballis, "Airport site selection based on multi-criteria analysis: the case study of the island of samothraki," Operational Research, vol. 3, no. 3, pp. 261-279, 2003.

[25] S. Onut and S. Soner, "Transshipment site selection using the AHP and TOPSIS approaches under fuzzy environment," Waste Management, vol. 28, no. 9, pp. 1552-1559, 2008.

[26] J. L. Rosenberg and A.-M. Esnard, "Applying a hybrid scoring methodology to transit site selection," Journal of Urban Planning and Development, vol. 134, no. 4, pp. 180-186, 2008. 
[27] V. Padmaja, S. S. Asadi, and M. A. Reddy, "Integrated analytical hierarchy processGIS model for landfill siting: a case study from India," in Proceedings of The Nineteenth International Conference on Solid Waste Technology and Management, pp. 155166, Philadelphia, Pennsylvania, 2007.

[28] B. Yu, H. B. Zhu, W. J. Cai, N. Ma, and B. Z. Yao, "Twophase optimization approach to transit hub location-the case of Dalian," Journal of Transport Geography, vol. 33, pp. 33-62, 2013.

[29] L. Dimitriou, "Optimal competitive freight network design as hierarchical variational inequalities programming problems," Transportation Research Part C: Emerging Technologies, vol. 55, pp. 116-138, 2015.

[30] A.-K. Rothenbacher, M. Drexl, and S. Irnich, "Branch-andprice-and-cut for a service network design and hub location problem," European Journal of Operational Research, vol. 255, no. 3, pp. 935-947, 2016.

[31] C. E. Shannon and W. Weaver, The Mathematical Theory of Communication, The University of Illinois Press, Urbana, Ohio, USA, 1947.

[32] M. Zeleny, Multiple Criteria Decision Making, Springer, New York, NY, USA, 1996.

[33] C. E. Shannon, "A mathematical theory of communication," Bibliometrics, vol. 5, no. 1, pp. 3-55, 2001.

[34] C. Cao and S. Slobounov, "Application of a novel measure of EEG non-stationarity as 'Shannon- entropy of the peak frequency shifting' for detecting residual abnormalities in concussed individuals," Clinical Neurophysiology, vol. 122, no. 7, pp. 1314-1321, 2011.

[35] S. Chen, Y. Leng, B. Mao, and S. Liu, "Integrated weight-based multi-criteria evaluation on transfer in large transport terminals: A case study of the Beijing South Railway Station," Transportation Research Part A: Policy and Practice, vol. 66, no. 1, pp. 13-26, 2014.

[36] R. K. Srivastav and S. P. Simonovic, "An analytical procedure for multi-site, multi-season streamflow generation using maximum entropy bootstrapping," Environmental Modeling and Software, vol. 59, pp. 59-75, 2014.

[37] A. Delgado and I. Romero, "Environmental conflict analysis using an integrated grey clustering and entropy-weight method: A case study of a mining project in Peru," Environmental Modeling and Software, vol. 77, no. 2, pp. 108-121, 2016.

[38] D. Y. Li, H. J. Meng, and X. M. Shi, "Membership clouds and membership cloud generators," Journal of Computer Research and Development, vol. 32, no. 6, pp. 15-20, 1995.

[39] L. Li, L. Liu, C. Yang, and Z. Li, “The comprehensive evaluation of smart distribution grid based on cloud model," Energy Procedia, vol. 17, pp. 96-102, 2012.

[40] L. J. Fan, Y. X. Ling, L. C. Liao, and B. X. Li, "An improved evaluation method based on cloud models for situation consistency within the battlefield of joint operations," Procedia Engineering, vol. 29, pp. 1590-1595, 2012.

[41] L. Zhang, X. Wu, L. Ding, and M. J. Skibniewski, "A novel model for risk assessment of adjacent buildings in tunneling environments," Building and Environment, vol. 65, pp. 185-194, 2013.

[42] C. B. Li, Z. Q. Qi, and X. Feng, "A multi-risks group evaluation method for the information project under linguistic environment," Journal of Intelligent \& Fuzzy Systems: Applications in Engineering and Technology, vol. 26, no. 3, pp. 1581-1592, 2014.

[43] L. Zhang, X. Wu, Q. Chen, M. J. Skibniewski, and J. Zhong, "Developing a cloud model based risk assessment methodology for tunnel-induced damage to existing pipelines," Stochastic Environmental Research and Risk Assessment, vol. 29, no. 2, pp. 513-526, 2015.

[44] Y. Ma and J. Xu, "A cloud theory-based particle swarm optimization for multiple decision maker vehicle routing problems with fuzzy random time windows," Engineering Optimization, vol. 47, no. 6, pp. 825-842, 2015.

[45] L. Wu, C. Zuo, and H. Zhang, "A cloud model based fruit fly optimization algorithm," Knowledge-Based Systems, vol. 89, pp. 603-617, 2015.

[46] W. H. Deng, G. Y. Wang, and X. R. Zhang, "A novel hybrid water quality time series prediction method based on cloud model and fuzzy forecasting," Chemometrics and Intelligent Laboratory Systems, vol. 149, pp. 39-49, 2015.

[47] J.-q. Wang, L. Peng, H.-y. Zhang, and X.-h. Chen, "Method of multi-criteria group decision-making based on cloud aggregation operators with linguistic information," Information Sciences, vol. 274, pp. 177-191, 2014.

[48] J.-Q. Wang, J.-J. Peng, H.-Y. Zhang, T. Liu, and X.-H. Chen, "An uncertain linguistic multi-criteria group decision-making method based on a cloud model," Group Decision and Negotiation, 2015.

[49] G. Wang, C. Xu, and D. Li, "Generic normal cloud model," Information Sciences, vol. 280, pp. 1-15, 2014.

[50] Y. Wu, K. Chen, B. Zeng, M. Yang, and S. Geng, "Cloud-based decision framework for waste-to-energy plant site selection-a case study from China," Waste Management, vol. 48, pp. 593603, 2016.

[51] X. Li, B. Huang, R. Li, and Y. Zhang, "Exploring the impact of high speed railways on the spatial redistribution of economic activities - Yangtze River Delta urban agglomeration as a case study," Journal of Transport Geography, vol. 57, pp. 194-206, 2016.

[52] China Railway Corporation and Southwest Jiaotong University, Research on Railway Express Freight Transport Organization Optimization Technology under the Conditions of Modern Logistics, Southwest Jiaotong University, 2016.

[53] National Statistics Bureau of the People's Republic of China, 2016, http://www.stats.gov.cn/.

[54] Ministry of Transport of the People's Republic of China, 2016, http://www.moc.gov.cn/.

[55] Ministry of Commerce of the People's Republic of China, 2016, http://www.mofcom.gov.cn/. 


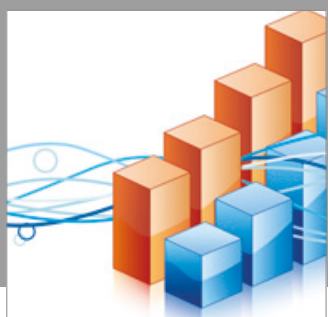

Advances in

Operations Research

vatersals

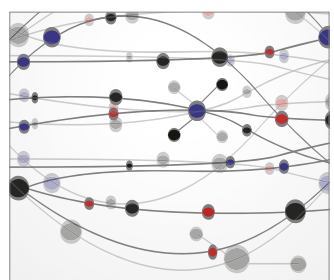

\section{The Scientific} World Journal
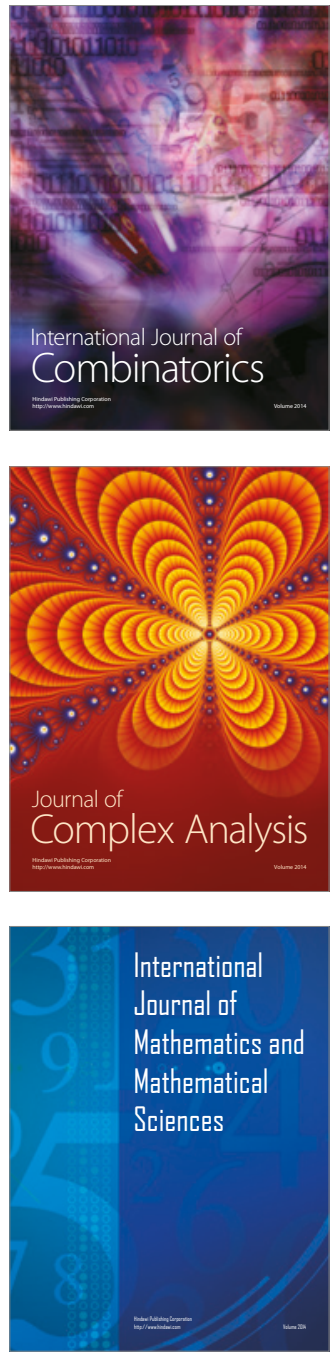
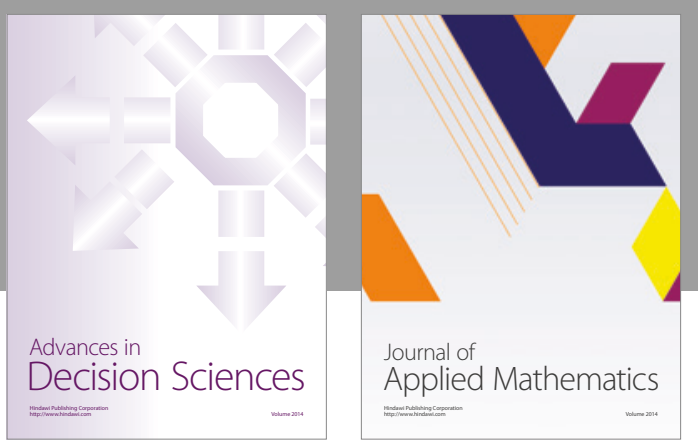

Algebra

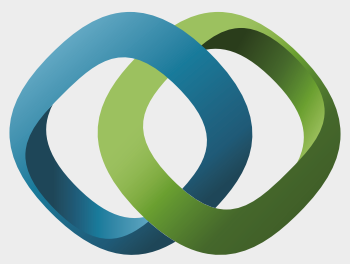

\section{Hindawi}

Submit your manuscripts at

https://www.hindawi.com
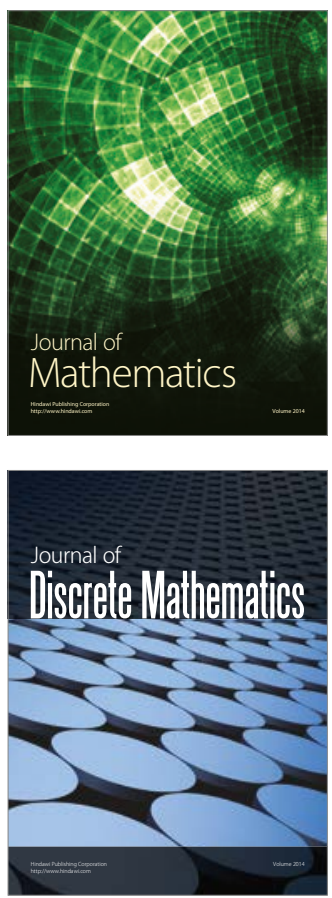

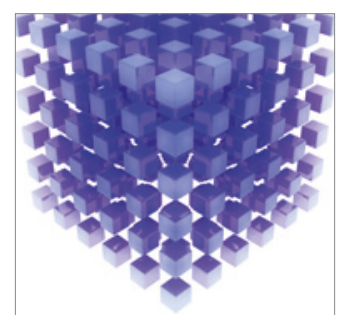

Mathematical Problems in Engineering
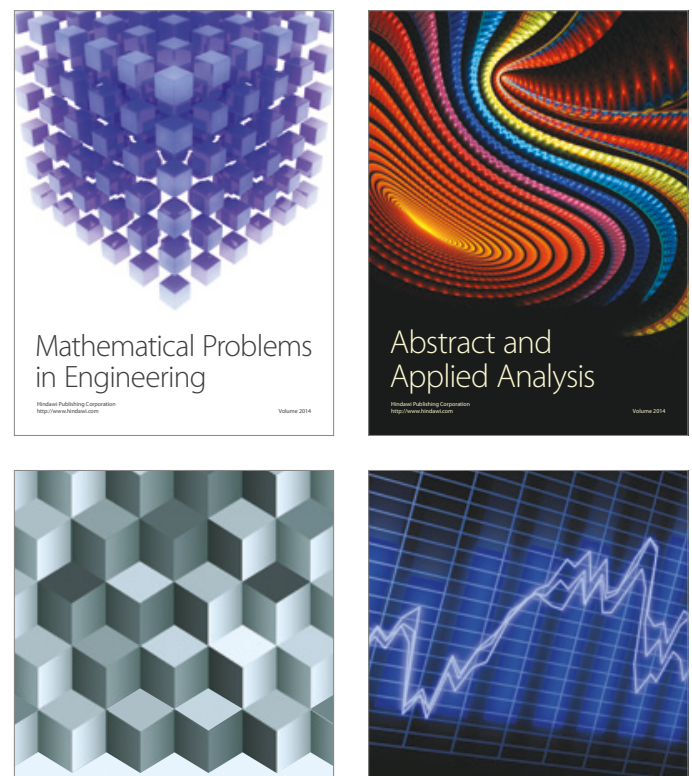

Journal of

Function Spaces

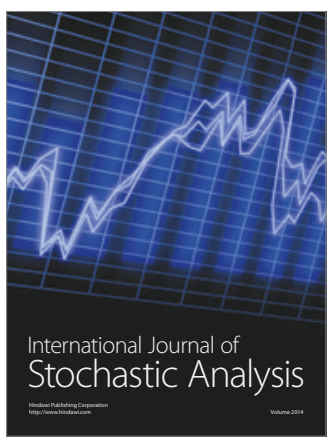

Probability and Statistics
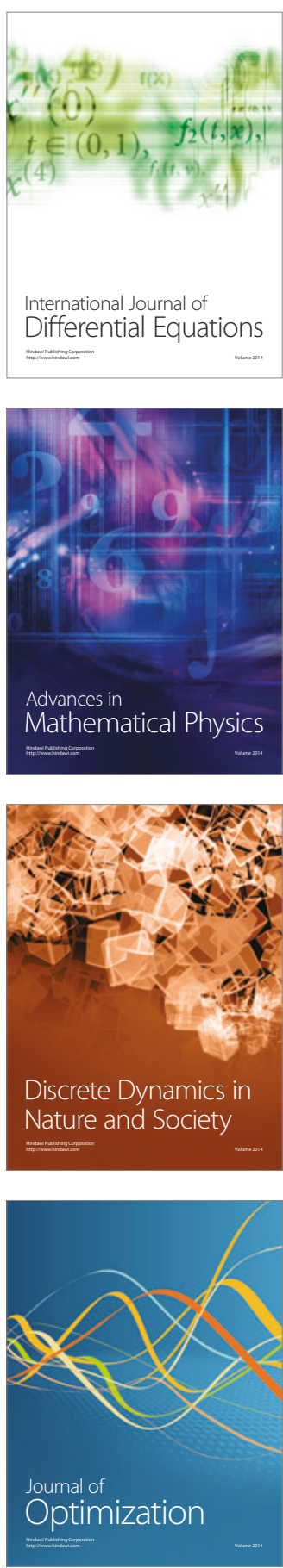